\title{
PECULIARITIES OF FOREIGN LANGUAGE AND CULTURE PERCEPTION BY BILINGUALS
}

\section{Devitska A. I.}

\section{INTRODUCTION}

After years of bilingualism studies, all the facts indicate that it has a positive effect on personality development, regardless of age. That is why educators in many countries emphasize the need to implement a policy of bilingualism in education. The facts show that the governments of most countries are pursuing a policy of monolingualism. Therefore, only $25 \%$ of nearly 200 countries recognize two or three official languages. But despite such a conservative government policy, more and more children are receiving education in several languages, and their numbers are already outnumbered by those who learn only one mother tongue. Pedagogical sources use the terms "bilingual learning" and "bilingual education", traditionally considering education as a process and a process result.

Today, bilingual learning is a means of gaining bilingual education and the process of forming a personality open to interaction with the outside world. Since, in the process of bilingual learning, foreign language is considered not only as a means of daily communication, but also as a tool for cognition of the world, special knowledge, they as a result achieve a high integrative level of linguistic and subject competence.

Bilingual learning contributes to broadening the students' worldview through comparative analysis of foreign language cultures, forming a tolerant attitude towards alternative views related to the national specificities of different peoples as well as stimulates the need for further education and selfdevelopment, which is a prerequisite for professional activity in the modern world. However, achieving these goals is only possible if the right model of bilingual learning is chosen, which should take into account the needs and capabilities of not only society but also students.

\section{Integration strategies and foreign language perception by immigrant bilinguals}

The expediency and principles of using multiple languages in education can be influenced by many factors, such as the linguistic diversity of a country or region, particular social and religious sentiment, or the desire to maintain one's cultural identity. The latest language education programs are often aimed at developing skills in languages of international communication, combining them with their mother tongue. The overall portrait of a foreign language 
education and learning policy in two or more languages is quite complex but at the same time amazing.

Bilingual linguistic behavior is seen as the process of choosing an option for constructing a socially correct expression, so aspects of language are perceived as socially conditioned variation in language. Therefore, scientists are trying to identify mechanisms for selecting socially relevant options, establish selection criteria as well as to find out social factors that influence the choice of variant.

The purpose of sociolinguistic analysis is to identify the social norms that determine the linguistic behavior of speakers. The main social components of bilingual linguistic behavior according to the scientist A. Schweitzer are referred to social roles, social statuses, orientation to certain social values and norms ${ }^{1}$. However, the researcher E. Vereshchagin believes that when analyzing behavior, it is obligatory to pay attention to the environment in which the communication occurs, whereas the choice of the topic, the use of familiar comparisons, hints, ways to support communication and non-verbal communication are important as well ${ }^{2}$.

All the participants in our phonetic experiment, the Slovaks, who immigrated to the United Kingdom, qualified their level of Slovak language competence as advanced. Surprisingly, even those respondents who have been living in the United Kingdom for over 20 years, confirmed that their level in Slovak language is advanced as well. This very fact testifies to linguistic patriotism and the willingness to preserve native linguistic traditions in emigration. In addition, this process significantly influences the value orientation in language choice of the Slovak speaker of English.

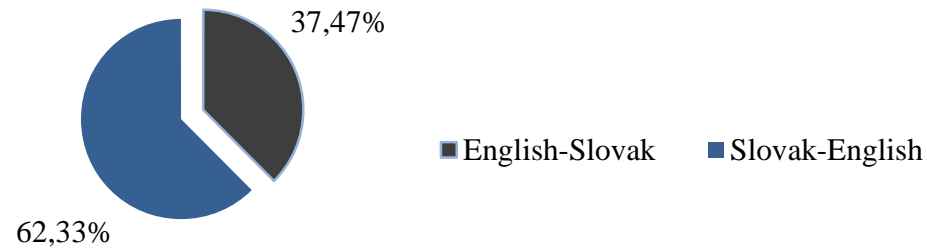

Pic. 1. Language priority in Slovak bilingual immigrants

As can be seen from the figure above, most of the speakers, who participated in an experimental-phonetic study, consider themselves to be English-Slovak bilinguals (that makes 62.33\%), despite the fact that they

1 Швейцер А. Д. К проблеме социальной дифференциации языка. Bonpocbl языкознания. Москва: Наука, 1982. № 5. С. 39-48.

${ }^{2}$ Верещагин Е. М. Психологическая и методическая характеристика двуязычия (билингвизма). Москва : Изд-во Моск. ун-та, 1969. 53 с. 
communicate in English daily in all possible spheres. In contrast, the second part of the speakers (that makes 37.67\%) indicated that they use Slovak language for every occasion and at any possibility. Moreover, $14 \%$ of them argued, that when communicating in English, they think in Slovak language, and that interpretation from English and into English is of great complexity for them.

As an example, we may look through Slovak bilinguals' responses, written in the questionnaires, in which they commented on the situations in which they switch into Slovak language. Thus, 35.78\% of total amount of the respondents, indicated that they alternate in both Slovak and English languages when they are in a state of stress, depression, fear, psychological pressure and frustration.

Therefore, those Slovak immigrants, who switch into Slovak after a situation of communication in English, in a state of excitement, excessive amazement and joy, make up $42.95 \%$ of the respondents, whereas, the other $18.03 \%$ of the speakers stated that they use Slovak language in any unexpected situations.

Due with the abovementioned facts, we can conclude that such a situational code-switching from English to Slovak and vice versa may be related, first of all, to the level of perception or non-acceptance of a foreign language culture by Slovak immigrants. These data were summarized in Pic. 2. It seems likely that a positive attitude (perception) is assimilation and integration, and a negative attitude (that is rejection) is characterized mainly by detachment and marginalization.

\begin{tabular}{|l|c|l|}
\hline \multirow{2}{*}{$\begin{array}{l}\text { Foreign } \\
\text { culture }\end{array}$} & Positive (+) & Negative (-) \\
\cline { 2 - 3 } perception & Integration & Separation \\
\cline { 2 - 3 } & Assimilation & Marginalisation \\
\hline
\end{tabular}

Pic. 2. The perception and rejection of foreign language culture by Slovaks

It is necessary here to clarify exactly what is meant by the term "adaptation". Actually, adaptation means adaptation to changing conditions, to a new environment ${ }^{3}$. If this definition is applied to Slovak immigrants, then a new environment for them will be a host culture (that is British one) and new social conditions, typical for Great Britain. Therefore, in relation to Slovak immigrants, the term sociocultural adaptation can be safely used. If immigrants consider themselves to be of another ethnicity, then a large sector of ethno-

${ }^{3}$ Redfield R., Linton R., Herskovits M. J. Memorandum for the study of acculturation // American Anthropologist, 1936, V. 38. P. 149-152. 
confessional adaptation is added to sociocultural adaptation as a whole. Moreover, in our case, we have labor immigrants, thus, we add one more adaptation, that is professional.

In terms of our research, acculturation is of high importance. The term is usually used to describe the process of mastering a foreign culture as a whole. It is assumed that the basis of this process is the interaction of two cultures (foreign and native) ${ }^{4}$.

As applied to different social groups, that are involved into our research, the term acculturation has been used to refer to situations in which we describe the directions of change in the original cultural models of interacting groups. At the level of an individual, a Slovak immigrant to United Kingdom, an acculturation is understood as the process of mastering the knowledge and skills necessary for living in a foreign culture. Thus, acculturation strategies include the direction vectors of changes in the initial cultural models of both groups and individuals.

In our research four strategies of acculturation are distinguished: 1) assimilation is a situation when a Slovak immigrant to UK fully accepts the values and norms of a different culture, while abandoning his own norms and values; 2) separation is a situation of denial of a foreign (English in our case) culture while maintaining Slovak's own (other names - isolation, autonomy); 3) marginalization that is a loss of connection with Slovak's own culture and lack of connection with the majority culture (this situation often arises due to discrimination from this culture); 4) integration is a process of maintaining a connection with the old culture and having a connection with the new one.

Therefore, the result of acculturation is a long-term adaptation to life in a foreign culture, including sociocultural adaptation, the ability to navigate freely in a new culture and society, to solve everyday problems in the family, at home, at work, during studies; psychological comprises well-being, good mental health as well as psychological satisfaction; economic one, that includes satisfaction with work, level of immigrants' professional achievements, immigrants' well-being in the new culture (it should be noted that this type of adaptation result has been discussed relatively recently).

While a variety of definitions of the term enculturation have been suggested, this paper will use the definition suggested by J. Berry, who saw it as the mastery of a person in the process of socialization of the norms of his own culture, but can, if desired, be used to describe the development of another culture ${ }^{5}$.

${ }^{4}$ Berry J. W. Acculturation as Varieties of Adaptation // A. Padilla (ed.), Acculturation: Theory, Models and Some New Findings. Boulder: West-view, 1980. P. 9-25.

${ }^{5}$ Berry J. W. Conceptual Approaches to Acculturation. In K. Chun, P. Balls-Organista, G. Marin (eds.), Acculturation: Advances in Theory, Measurement and Applied Research. Washington: APA Books, 2003. P. 17-37. 
In both cases, when talking about enculturation, they try to focus on training. This emphasis is also reflected in the definitions of enculturation, as the following examples of definitions illustrate well. Enculturation is a gradual development of skills, manners, and behavioral norms by a person that are characteristic of a certain type of culture ${ }^{6}$. Enculturation is a long and gradual development by a person of methods, norms, practical recommendations in everyday life as well as the formation of cultural competence in relation to the standards of the society in which a person lives.

Mainly, enculturation is a process that allows Slovak immigrant to master a whole system of cultural norms, a system of value orientations and preferences accepted in society; etiquette norms of behavior in different life situations; generally accepted approaches to the interpretation of various phenomena and events; the foundations of the socio-political structure of this society; national traditions, customs; the prevailing morality, as well as worldview; the prevailing fashion, styles, symbols, regalia; national authorities; political and cultural history of the society and main symbols of national dignity, pride, etc.

Among the psychological mechanisms, or rather, adaptation tools, are two fundamentally there appear to be different processes: imitation and identification (acceptance). The first process is more appropriate for temporary Slovak immigrants, the second one is for those who adapt for a long time to a new culture. Concluding the description of the acculturation process in Slovak immigrants to the United Kingdom, it should be noted that reaching agreement on understanding of commonly used terms and describing the mechanisms of sociocultural adaptation is a necessary but not sufficient condition for an effective dialogue. In order for this dialogue to really contribute to improving the adaptation of Slovak immigrants, it is also necessary to agree on a current number of problems arising in connection with immigration flows.

And the range of these problems is wide: from the legal status of immigrants to their psychological comfort. Among the most acute problems we would attribute intolerance and its prevention (in particular, in United Kingdom); legal and economic factors of intercultural communication; prospects for enculturing children from immigrant families (both for their native and host cultures).

Analysis of the data provided in the questionnaires written by Slovak immigrants in United Kingdom showed that the formation of prosodic interference in the English language of the Slovaks is significantly influenced by a number of factors, among which special attention is drawn to the following: linguistic, mental, psychological, cognitive and extralinguistic ones. In terms of our research we analyzed the factors that cause low, medium and

${ }^{6}$ Brislin R. W., Cushner K., Cherrie C., Yong M. Intercultural interactions: A practical guide, 1986, Beverly Hills, CA: Sage. 
high levels of phonetic interference in English-speaking Slovaks, the immigrants to the United Kingdom. Moreover, those very factors strongly affect the ability to properly convey the pragmatic purpose of narrated fragments of literary texts.

After analyzing the factors mentioned by the Slovak speakers in the questionnaires, we attempted to summarize them in the following scheme.

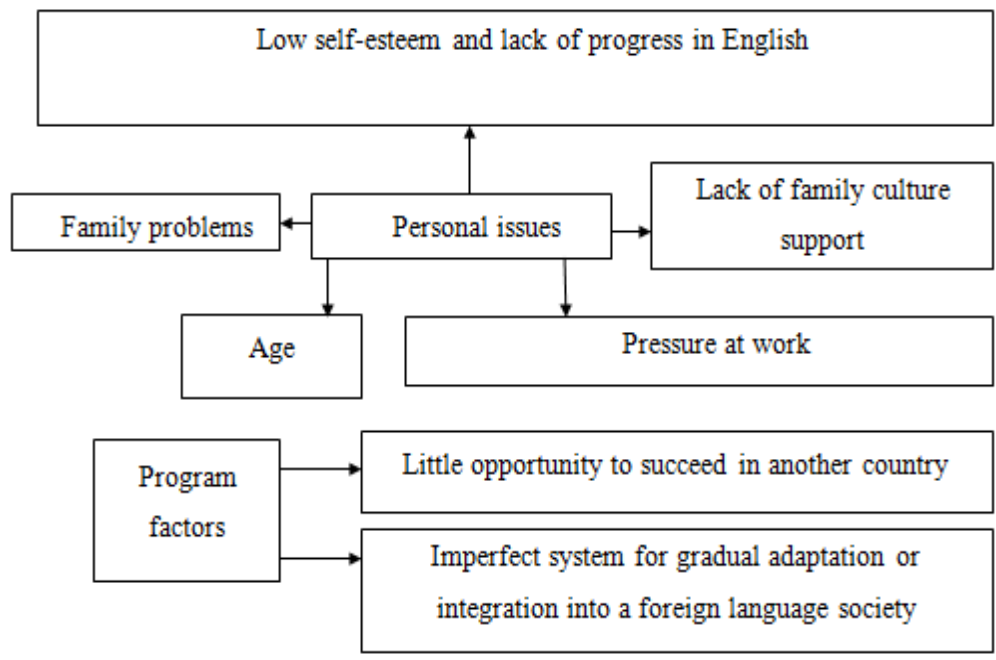

\section{Pic. 3. Factors contributing to low, medium and high level of phonetic interference in English spoken by Slovaks}

The abovementioned scheme presents two groups of factors that, in our opinion, cause middle and high levels of phonetic interference in English speech of the Slovak immigrants, among them are the following:

1) personal problems (including low level of self-esteem in combination with no progress in English, family problems as well as lack of support for family culture, age of the Slovaks and daily stress at work);

2) program factors (namely, lack of ability to succeed in another country and imperfect system for gradual adaptation / integration into a foreignlanguage society).

Another significant aspect for the immigrants is the process of awareness of immigrants' ethnic identity, therefore, it takes place in different ways, both at the level of individuals and in different situations of interaction, for example, whether they live in a multi-ethnic or mono-ethnic environment. It is obvious, that the multi-ethnic environment develops much faster and gives the individual more opportunities to acquire knowledge about the characteristics and differences of his ethnic group from other groups as well as forms and develops intercultural interaction skills. 
Thus, ethnic awareness is formed earlier, ethnic identity is more clearly recognized if socialization took place in a multi-ethnic environment (for example, in United Kingdom). In individuals living in a multi-ethnic environment, ethnic identity is more vivid and represented whereas among individuals living among culturally similar groups, awareness of their own ethnicity does not become a vital problem.

Moving on now to consider the features of the formation of ethnic identity, it should be noted that they also depend on which group the individual belongs to, whether the group of the majority or minority one. Likewise, children of minority groups tend to identify with the dominant group, which reflects the early awareness of children about the existence of a certain social structure, that in society some groups are rated higher than others ${ }^{7}$. But with age and the development of ethnic identity, members of ethnic minorities usually experience a shift to "intragroup orientation".

\section{Prosody analysis in Slovak-English bilinguals' English speech as a result of foreign culture integrity}

As was mentioned in the previous chapter, integration and acculturation factors strongly influence the perception of the foreign language and culture by immigrants, the Slovaks, who live in United Kingdom. Turning now to the experimental evidence on the ability to properly convey the pragmatic purpose of the utterances, narrated by Slovak-English bilinguals.

According to the analysis of the Slovak speakers' responses whether they managed to properly convey the pragmatic purpose of the utterances, we have summarized the following data. Most of the speakers believe that they have managed to convey the pragmatic purpose of the literary text narrated, for example, "Tea at the Midland" (85\%), "In Another Country" (70\%), "The Silkworm" (60\%) and "The Cuckoo’s Calling" (65\%).

At the same time, $30 \%$ of the Slovak speakers are not sure that they have been able to convey the pragmatic purpose of the utterances correctly. Meanwhile, another group of the speakers made it clear that their narration did not contribute to the correct convey of pragmatic purpose of the utterances, mainly in the following literary works "In Another Country" (15\%), "The Silkworm" (5\%).

Author's short prose texts, such as "Tea at the Midland" and "In Another Country" are written by a British writer David Constantine. Those very texts that were chosen for narration by native speakers of the Slovak language contain more situations with dialogues than the fragments of the detective novels, like "The Silkworm" and "The Cuckoo's Calling," which, in contrast, are characterized by the predominance of monologue speech. As the results of

${ }^{7}$ Белинская Е.П., Стефаненко Т.Г. Этническая социализация подростка. Воронеж, 2000. C. 7. 
the analysis of Slovak speakers' questionnaires showed, the reading of the dialogues turned out to be easier than reading the monologic excerpts of the literary texts.

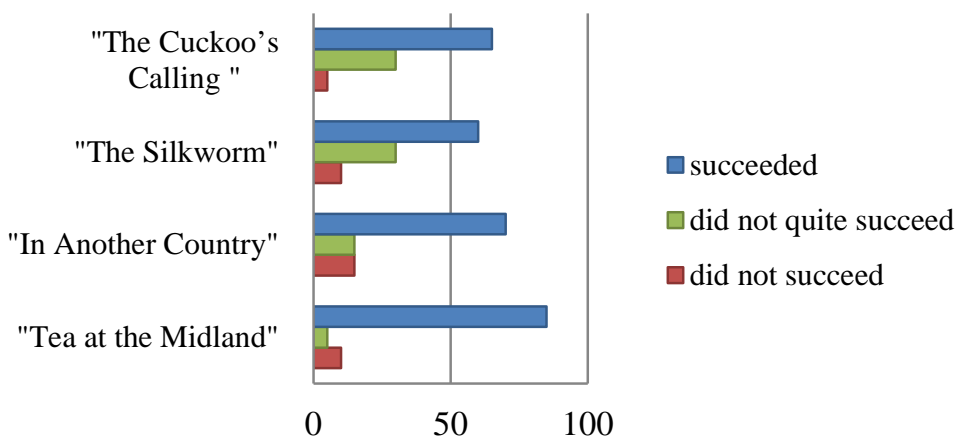

Pic. 4. The level of pragmatic purpose convey in literary works by the Slovak speakers with low, medium and high level of phonetic interference (according to the Slovak speakers' data)

Among the difficulties in the perception and narrating literary works in English, the Slovak speakers noted the difficulty in pronouncing unfamiliar words as well as a number of grammatical constructions that made it impossible to convey the emotional saturation and pragmatic purpose of literary texts.

On the other hand, the results of an auditive analysis conducted by phoneticians, the teachers of English, who have evaluated the extent of the meaning and pragmatic purpose of narrated texts seem to be different and are presented in the following diagram.

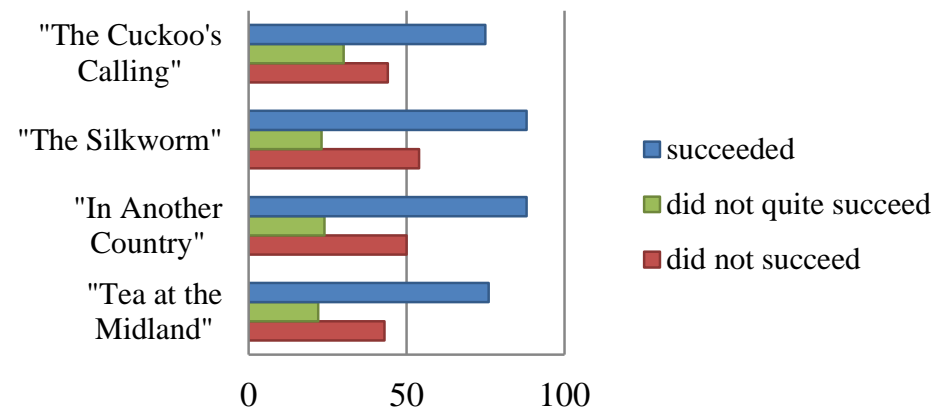

Pic. 5. The level of pragmatic purpose convey in literary works by the Slovak speakers with low, medium and high level of phonetic interference in their English speech (according to phoneticians' data) 
It should be explained that the vertical axis in picture above defines the degree of emotional saturation and pragmatic potential convey in narrated fragments of literary texts by the Slovak speakers. At the same time, the horizontal axis on the diagram indicates the number of texts listened by the auditors.As can be seen in the figures, the data on the degree of emotional saturation and pragmatic potential convey in narrated fragments of literary texts by Slovak speakers are somewhat different.

The informant auditors found that Slovak speakers with low level of phonetic interference were able to convey the emotional saturation and pragmatic purpose in all four narrated texts. The English speaking of the Slovaks with medium level of phonetic interference was qualified by the informants as not entirely clear, with some errors in pronunciation that sometimes affected the emotional saturation and pragmatic potential convey in narrated fragments of literary texts.

Incorrect realization of emotional saturation and pragmatic potential in narrated fragments of literary texts characterize English speech of the Slovak speakers with high level of phonetic interference. However, an analysis of Slovak speakers' questionnaires, allowed us to conclude, that despite the daily need to use English at the professional and household levels, those Slovaks, the immigrants to the United Kingdom, retain their identity through the use of the Slovak language at every opportunity, care about their people's cultural heritage and traditions, etc., which testifies to linguistic patriotism and directly influences the prosodic formation of statements, actualized in foreign language, that is English.

During the experiment, the phoneticians have characterized and analyzed English language standard and interfered utterances, narrated by Slovak-English bilinguals. While analyzing, the experts have identified violations detected in the speakers' interfered speech at the suprasegmental level, including logical division of the expression into intonation (syntagm) groups; the correctness of division of expression into syntagms (intonation groups); distribution of phrase emphasis (nuclear, non-nuclear, partial) in words; the correctness of the prosodic pattern of the semantic center of the intonation group (syntagm) and its localization; the correctness of the selection of the most important information center in the semantic structure of the text; definition of linguistic means by which it is allocated; participation of intonation components in the expression pattern, namely the melody component (the tone level of the beginning of the intonation groups, range, interval, direction of pitch in preterminal and terminal sections of intonation groups in standard and interfered statements as well as phrasal emphasis, rhythm, volume (high, moderate, low), tempo (fast, moderate, slow), pauses, timbre; informative sections of the intonation contour while conveying the meaning of the statement (intonation group); prosodic means of transmission of emotional saturation of expression (degree of emotions 
arousal); prosodic means of conveying a pragmatic purpose of the utterance / principal expression of the utterance / text.

The results of the auditive analysis showed that Slovak speakers of English with a high degree of phonetic interference show a greater fragmentation of syntagmatic division, which can be explained by a large number of intonation groups in the statements. Therefore, such intonation groups are perceived as short and include numerous actualizers, conjunctions etc.

At the same time, inadequacy of the melodic component of intonation in the fragments of English narrated texts realized by the Slovak speakers of English is noted as well. Thus, the auditors argued that in the interfered utterances, the low or average beginning of the utterances was replaced by a high one, which does not coincide with standard British variant and marks accented English speech of the Slovaks.

Moreover, the prosodic pattern of the standard statement is characterized by actualization with the help of neutral intonation parameters, namely the predominance of the truncated variety of scale in intonation groups, there is no ascending terminal tone, which gives the standard speech a certain degree of emotionality, and also eliminates monotonous sounding.

Similarly, the prosodic pattern of the fragment narrated by a Slovak speaker of English with a low degree of interference is almost indistinguishable from the standard one. The statement is characterized by the predominance of the truncated variety of the scale, the absence of the use of ascending terminal tone, the extension of tonal intervals, modifications of the tonal range and the dominance of the ascending-descending melodic outline of the intonation group, which makes English speech of the Slovaks sound emotional and eliminates monotonous sounding.

In addition, the correct intonation of the expression in the correlation with proper emotional and semantic saturation performs functual meaning as it complements and intensifies the semantic centers of the fragment, enhances its rhythmicity as well as gives it a special expressive coloring and promotes the level of its emotional saturation and pragmatic purpose. Such proper characteristics in English speech of the Slovaks shows their similarity to the standard pronunciation.

It should also be noted that a moderate tempo of speech plays an important role in enhancing the audience's interest while narrating. Thus, the smooth, legato rhythm inherent in the standard variant of statements with a high level of emotional and pragmatic potential is formed by regular alternation of stressed and unstressed syllables within the intonation group. The functioning of a rhythm of this kind is associated with the expression of deep and sincere feelings when, for example, the native speaker expresses a positive assessment of the main character, his admiration for his or her high moral qualities.

At the same time, phoneticians, the auditors, have classified the speech of the Slovak speakers of English with a medium level of phonetic interference 
as one that conveys the literary work's expressiveness and emotionality to a sufficient degree, which, accordingly, significantly increases the level of transmission of emotional and pragmatic expression.

In contrast, the auditors argued that Slovak speakers of English with a high degree of phonetic interference are characterized by unnaturally high tone level of the beginning of intonation groups in combination with the allocation of semantic centers, which differs from those in standard realizations. Moreover, those narrated texts show the absence of a greater degree of dominance of wordintensifiers as well as a greater refinement of the syntagms (12) that do not coincide with the standard. Besides, the usage of low rising tone in combination with incorrect division into semantic groups, excessive increase in number and different duration of pauses proves the uncertainty in pronunciation and Slovak speaker's lack of knowledge of particular words used in the literary text.

At the same time, Slovak speakers' utterances contain a lot of indefinite articles, although they are absent in the standard variant of the text. This mistake may be explained by a lack of language competence as well. In addition, incorrect pronunciation of the words, an excessive vowel elongation, incorrect pronunciation of proper names and the use of double accent leads to a violation in the conveying the meaning and emotional saturation of the literary text.

Therefore, the Slovak speakers of English with a high level of phonetic interference are characterized by the use of a wide tonal range instead of an average one, accelerating the tempo rather than slowing it down. As for the volume of speech production, so the specified speaker group uses mostly high volume while narrating, which perceives as unnatural and sometimes rude.

The whole set of characteristics obtained through auditive analysis reflects on the degree of emotional expression and change in pragmatic purpose. Therefore, in the standard English speech, the level of emotional and pragmatic expression is qualified as high. In contrast, the level of emotional and pragmatic expression of the speakers with high level of phonetic interference was noted as low. The phoneticians also emphasized that the speakers of this group failed to convey the emotionality of the literary text completely, their speech sounded like a simple statement of facts, that is boring and monotonous.

Summarizing the above mentioned, it seems appropriate to highlight the prosodic characteristics of English spoken by the Slovak immigrants with a high degree of phonetic interference. Thus, the intonation level of their speech inherent a narrow range of melodic contour, a large number of syntactically unjustified pauses, speech in high tones or, conversely, monotonous with limited melodic complex, increasing the frequency of equal scales and tones (equalizing melodic contour is due to narrowing) intensity, increasing the role of dynamic and temporal components as a means of emphasis.

In contrast, smoothness of melody, diverse melodic repertoire, wide range of melodic contour, preferred use of patterns with a strong beginning, unity of melody and dynamics as well as full sound quality of voice, ensured by 
the intensity of articulation and the uniform distribution of energy across a wide range of spectra, these regularities of supra-segmental characteristics depict English speech of the Slovaks with a high level of foreign language competence.

Thus, phonetic auditors identified the number of violations in the distribution of phrasal emphasis and the division of the speech stream into intonation groups in all narrated interfered utterances and stated the following: in English speech of the Slovaks with a low degree of phonetic interference only $10 \%$ of violations were recorded of the total number of texts narrated.

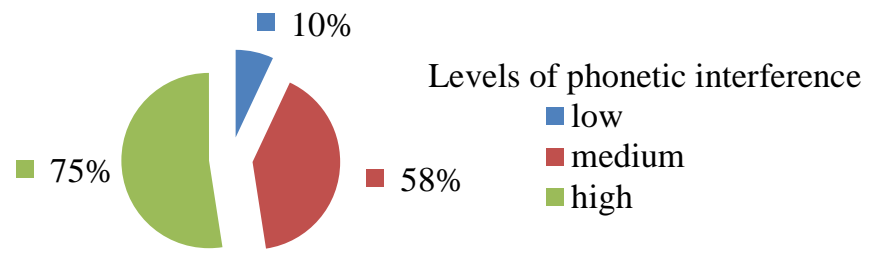

\section{Pic. 6. Deviations in Phrase Stress Distribution in English Interfered Utterances (according to phoneticians' data)}

Speakers with an average level of phonetic interference committed the above mentioned errors in 58\% of cases. English speech of the Slovak immigrants with a high degree of phonetic interference is characterized by the presence of the maximum number of violations in the distribution of phrase stress and incorrect division of speech flow on intonation groups and makes $75 \%$ of the total number of literary texts.

Consequently, phoneticists argued that the variation of phrase stress in the interfered utterances, narrated by the speakers with low, medium, and high levels of phonetic interference, often depend on many factors, such as understanding the context, its perception ot rejection, communicative situations as well as psychological and emotional condition of the speakers while narrating the literary works.

Moreover, it is obvious, that the level of education, social status, individual characteristics, experience of narrating the text, mood and desire at the moment of the narrating the material, some extra-linguistic factors influence the proper convey of the meaning in the literary text.

The utterances realized by the native speakers of English show isochronous pronunciation of pronounced syllables, as well as the division of utterances into average intonation group duration, the same isolation and pronunciation of full words, rhythmicity and isochronicity of pronunciation of pronounced syllables, chanting and give them a special sounding, typical for a standard realization. 
English spoken by a Slovak speaker with a low degree of phonetic interference is close to the standard variant of narration in terms of distribution and localization of phrase emphasis. However, there are differences in the intonational pattern of the narrated utterances, in particular: indifferent isolation of the stressed syllables, some changes in the implementation of the utterance at the melodic level indicate on the individual features of his perception and understanding of the speaker.

Therefore, the realizations produced by the Slovak speakers of English with medium and high phonetic interference are characterized by the nuclear tone on proper names, which creates a monotonous and colorless sounding and is in violation of the English standard. Such violations point to the peculiarities of the interaction of the prosody in interfered English speech of the Slovaks and often lead to the unnatural sounding of the utterances.

Meanwhile, literary texts narrated by English speakers tend to express a high degree of emotional and pragmatic potential with the help of long intonation groups (3-4 rhythmic groups) and full emphasis on the communication centers expressed by the parts of the language (prepositions, particles, conjunctions). It is through such intonational pattern of standard statements that the communication centers that focus the theme of the whole text are selected. Moreover, a peculiar rhythmic scheme of highlighting pronounced syllables of meaningful words enhances the structural completeness of each intonation group, indicating a semantics and informational background.

\section{CONCLUSIONS}

After years of bilingualism studies, all the facts indicate that it has a positive effect on personality development, regardless of age. That is why educators in many countries emphasize the need to implement a policy of bilingualism in education. The facts show that the governments of most countries are pursuing a policy of monolingualism.

The expediency and principles of using multiple languages in education can be influenced by many factors, such as the linguistic diversity of a country or region, particular social and religious sentiment, or the desire to maintain one's cultural identity. The latest language education programs are often aimed at developing skills in languages of international communication, combining them with their mother tongue. The overall portrait of a foreign language education and learning policy in two or more languages is quite complex but at the same time amazing.

Bilingual linguistic behavior is seen as the process of choosing an option for constructing a socially correct expression, so aspects of language are perceived as socially conditioned variation in language. Therefore, scientists are trying to identify mechanisms for selecting socially relevant options, establish selection criteria as well as to find out social factors that influence the choice of variant. 
English speech of the Slovaks as a result of a situational code-switching from English to Slovak and vice versa may be related, first of all, to the level of perception or non-acceptance of a foreign language culture by Slovak immigrants. As applied to different social groups, that are involved into our research, the term acculturation has been used to refer to situations in which we describe the directions of change in the original cultural models of interacting groups. At the level of an individual, a Slovak immigrant to the United Kingdom, an acculturation is understood as the process of mastering the knowledge and skills necessary for living in a foreign culture. Thus, acculturation strategies include the direction vectors of changes in the initial cultural models of both groups and individuals.

\section{SUMMARY}

The study deals with the comprehensive study of peculiarities of foreign language and culture perception by bilinguals as well as prosodic characteristics of interfered English Speech of the Slovaks, who immigrated to the United Kingdom.

The experimental research outcomes have shown that English spoken by the Slovak speakers with a low degree of phonetic interference is close to the standard variant of narration in terms of distribution and localization of phrase emphasis. However, there are differences in the intonational pattern of the narrated utterances, in particular: indifferent isolation of the stressed syllables, some changes in the implementation of the utterance at the melodic level indicate on the individual features of his perception and understanding of the speaker.

Therefore, the realizations produced by the Slovak speakers of English with medium and high phonetic interference are characterized by the nuclear tone on proper names, which creates a monotonous and colorless sounding and is in violation of the English standard. Such violations point to the peculiarities of the interaction of the prosody in interfered English speech of the Slovaks and often lead to the unnatural sounding of the utterances. Analysis of the data provided in the questionnaires written by the Slovak immigrants in United Kingdom showed that the formation of prosodic interference in the English language of the Slovaks is significantly influenced by a number of factors, among which special attention is drawn to the following: linguistic, mental, psychological, cognitive and extralinguistic ones. 


\section{REFERENCES}

1. Белинская Е. П., Стефаненко Т.Г. Этническая социализация подростка. Воронеж, 2000. С. 7.

2. Верещагин Е. М. Психологическая и методическая характеристика двуязычия (билингвизма). Москва : Изд-во Моск. ун-та, 1969. 53 с.

3. Швейцер А. Д. К проблеме социальной дифференциации языка. Вопросы языкознания. Москва: Наука, 1982. № 5. С. 39-48.

4. Redfield R., Linton R., Herskovits M. J. Memorandum for the study of acculturation // American Anthropologist, 1936, V. 38. P. 149-152.

5. Berry J. W. Acculturation as Varieties of Adaptation // A. Padilla (ed.), Acculturation: Theory, Models and Some New Findings. Boulder: Westview, 1980. P. 9-25.

6. Berry J. W. Conceptual Approaches to Acculturation. In K. Chun, P. Balls-Organista, G. Marin (eds.), Acculturation: Advances in Theory, Measurement and Applied Research. Washington: APA Books, 2003. P. 17-37.

7. Brislin R. W., Cushner K., Cherrie C., Yong M. Intercultural interactions: A practical guide, 1986, Beverly Hills, CA: Sage.

\section{Information about the author:}

Devitska A. I.

Candidate of Philological Sciences, Associate Professor at the Department of Theory and Practice of Translation

Uzhhorod National University 45, office 503, Universytetska str., 88000, Uzhhorod, Zakarpattia region, Ukraine 